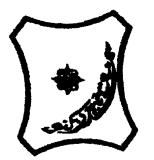

Bayero Journal of Pure and Applied Sciences, 10(2): 292 - 299

Received: March, 2017

Accepted: December, 2017

ISSN $2006-6996$

\title{
PHYTOCHEMICAL COMPOSITION AND ANTITRYPANOSOMAL ACTIVITY OF THE LEAF EXTRACT OF Leptadenia hastata (Pers) Decne
}

\author{
Haruna, A., ${ }^{1}$ Mann, A., $^{1 *}$ and Ogbadoyi, E.O. ${ }^{2}$ \\ 1, ${ }^{*}$ Department of Chemistry, Federal University Technology, Minna, P. M. B. 65, Niger State, Nigeria \\ ${ }^{2}$ Department of Biochemistry, Federal University of Technology, Minna, Niger State, Nigeria \\ *Correspondence author: +2348034295656, abdumann@gmail.com
}

\begin{abstract}
ABTRACT
Medicinal plants have been used to manage various human and animal diseases in many cultures globally. Nigeria is blessed with vast reservoir of herbs for the ethnomedicinal treatment of trypanosomiasis. The present study was to evaluate the phytochemical composition and antitrypanosomal activity of Leptadenia hastata leaf extract.The leaf sample was subjected to extraction by percolation method and the crude extract further partitioned into solvent- soluble fractions. Anti-trypanosomal activity screening was conducted using Trypanosomabrucei brucei infected mice. The results of the phytochemical analysis indicated alkaloids, saponins, tannins, flavonoids, terpenoids and anthraquinones were present. The result obtained from the antitrypanosomal activity screening indicated that the crude extract exhibited significant antitrypanosomal activity through reducing parasitaemia by $70 \%$. Moreover, the most potent antitrypanosomal effect was recorded by the dichloromethane partitioned fraction. GC-MS analysis of the derived fractionshowed phthalic, 1, 2-benzenedicarboxylic, hexadecanoic and octadecanoic acids. These bioactive compounds which are mainly carboxylic acid derivatives may be responsible for the observed antitrypanosomal activity of the extract.
\end{abstract}

Keywords: antitrypanosomal, Leptadenia hastata, phytochemical analysis

\section{INTRODUCTION}

Trypanosomiasis known as sleeping sickness affects man and animals. It is a parasitic disease caused by a trypanosome which is usually transmitted by testse fly (Glossonia sp) bites. The most popular forms of trypanosome transmitted in tropics are: Trypanosoma brucei gambiense (T.b.g), Trypanosoma brucei rhodesiense (T.b.r) and Trypanosoma cruzi (Hotez and Kamath, 2009). Trypanosomiasis lead to death of about 2 million cattle annually and this resulted in decrease in calving by $20 \%$ and milk production by $25 \%$. The use of chemotherapy for treating African trypanosomiasis is faced with numerous problems of availability, side effect, toxicity and expensive nature of drugs. Therefore, the poverty in many developing countries where animal rearing is a major occupation forms the basis for seeking for alternative, better and cheaper bioactive compounds to treat trypanosomiasis. Medicinal plants have organs that contain chemical substances that could be used for therapeutic purposes or are precursors in drug synthesis (Burkill, 2007). Many Nigerian plant extracts have been known to exhibit antitrypanosomal activity (Ogbadoyi et al., 2011; Abiodun et al., 2012; Ibrahim et al., 2014).

Leptadenia hastate (Asclepiadaceae) is commonly known in some West African countries because of its various applications. For instance, the leaf extract from L. hastata has been used to manage Onchocerciasis in Mali (Togola et al., 2008); scabies in Chad (Betti et al., 2011); hypertension, catarrh and skin diseases in Nigeria (Dambatta and Aliyu, 2011); trypanosomiasis, skin diseases and wound-healing in Burkina Faso and Nigeria (Tamboura et al., 2005). A number of pharmacological activities on the extracts of different parts of $L$. hastata exhibited some effects on common microbes as described by Aliero and Wara (2009). Despite the above advantages, in addition, $L$. hastata is also used by the Nupe people in Nigeria to treat African trypanosomiasis, but it has not been fully evaluated for anti-trypanosomal activities and phytochemical constituents. The aim of this research is to determine the phytochemical composition and anti-trypanosomal activity of $L$. hastata leaf extract.

\section{MATERIALS AND METHODS}

Reagents and chemicals

All the reagents used for the research were of analytical grades and obtained from the Department of Chemistry, Federal University of Technology, Minna, Nigeria. They include distilled water, $n$-hexane, dichloromethane, ethyl acetate, n-butanol, silica gel, methanol, and normal saline.

Apparatus and equipment

These include: percolator, milling machine, rotary evaporator, glass bottles, glass column, glass wool, GC-MS spectrometer, micro-hematocrit centrifuge, water bath, Whatman filter paper, measuring cylinders, hand gloves, masking tape, beakers, syringes, spatula, and weighing balance.

Collection of plant material

The fresh leaves (Plate 1) of Leptadenia hastata were collected from Beji, Bosso Local Government Area of Niger State in the month of June, 2014. 
The plant was botanically identified by Mal Muazzim Ibrahim of the Herbarium Unit of the Department of Medicinal Plant Research and Traditional Medicine,
National Institute for Pharmaceutical Research and Development, Garki - Abuja, Nigeria where voucher specimen was deposited.

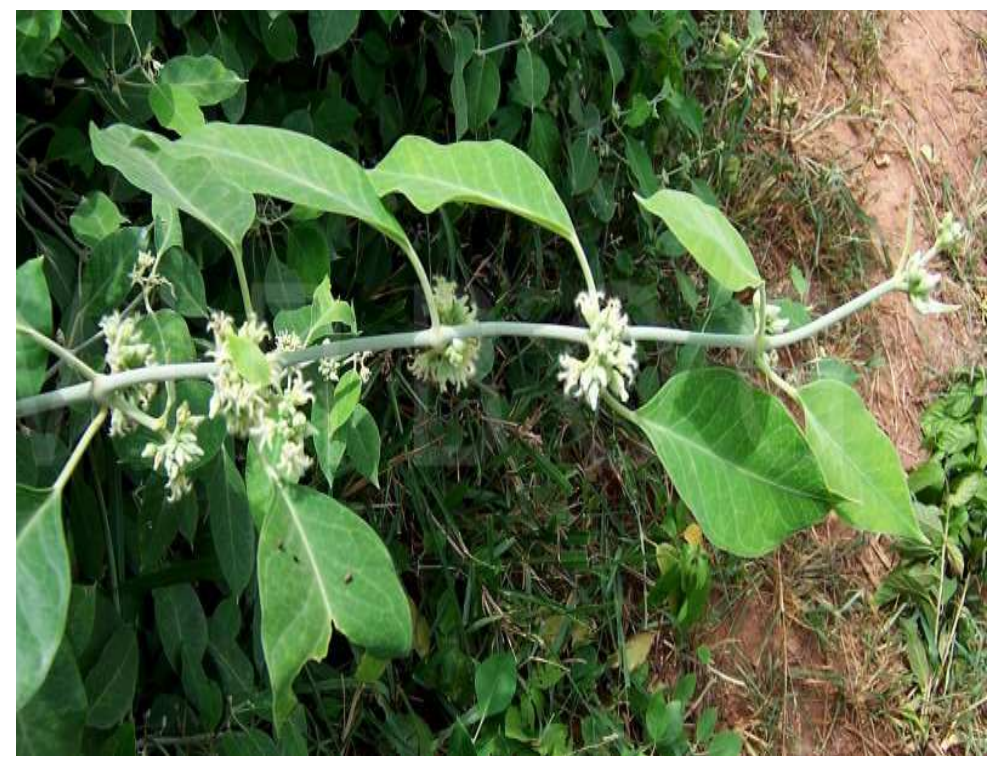

Plate I: The leaves of Leptadenia hastata Pers Decne

\section{Experimental Animals}

The experimental animals and parasite used were obtained from the National Institute for Trypanosomiasis and Onchocerciasis Research (NITOR), Kaduna State, Nigeria and subsequently maintained in Biochemistry Laboratory of Federal University of Technology Minna, Niger State were used for the study.

\section{Preparation of plant extract}

The leaves of Leptadenia hastata collected were washed with tap water to remove dirt, shed dried and pulverized into fine powder. The plant extract solution was obtained by percolating $300 \mathrm{~g}$ of the powdered leaf sample in $70 \%$ methanol using the cold maceration method at room temperature for $72 \mathrm{~h}$. The extract collected was concentrated using a rotary evaporator (R E-6000) to obtain the crude extract (Mann et al., 2011). It was further air dried and packed in glass bottle with proper labeling kept under refrigeration at $4^{\circ} \mathrm{C}$ and away from light by wrapping with aluminium foil until required for use.

\section{Phytochemical Screening of Crude Extract}

The phytochemical screening was carried out on the crude extract of the leaf sample to identify the metabolites qualitatively and quantitatively, namely: alkaloids, flavonoids, saponins, steroids, tannins, terpenoids, anthraquinones, resins and phenols using standard methods (Harborne, 1998; Trease and Evans, 1989).

\section{Partitioning of the Crude Plant Extract}

Thirty grams $(30 \mathrm{~g})$ of the crude extract was dissolved in water $\left(1000 \mathrm{~cm}^{3}\right)$ to give the aqueous Layer. Solvents used in order of their increasing polarities were $n$-hexane, dichloromethane, ethyl acetate, nbutanol (Mann, 2007). All of the fractions obtained were filtered twice to ensure the removal of residue using Whatman No1 filter paper (Whatman Biometra, Gottingen, Germany). Each fraction was concentrated in vacuo by the evaporation of the various solvents under reduced pressure at $35^{\circ} \mathrm{C}$ using rotary evaporator (R E-6000) to obtain the various solvent soluble fractions (Mann et al., 2011).

\section{Column Chromatography}

The Column was packed using wet packing method. Slurry was prepared by shaking $200 \mathrm{~cm}^{3}$ of hexane with silica gel and then packed in a column. The silica gel was first activated in the oven for $2 \mathrm{~h}$ at $105^{\circ} \mathrm{C}, 1$ $\mathrm{g}$ of the extract was re-dissolved in fifty $\left(50 \mathrm{~cm}^{3}\right)$ of methanol and $20 \mathrm{~g}$ of the activated silica gel was used to absorb the dissolved extract. The dissolved extract was kept under the fan to dry. The dried absorbent (silica gel) was then introduced to the top of the packed column and a piece of glass wool or filter paper was placed gently on top of the column. Elution was then carried out using gradient mixtures of $n$ hexane, $n$-hexane-ethylacetate and methanol (Mann et al., 2011).

\section{GC-MS Analysis}

GC-MS analysis was carried out on a Shamadzu (Kyoto, Japan) GC-MS model QP 2010 at National Research Institute for Chemical Technology, Zaria, according to the EN 14103 standard method (Orishadipe et al., 2010; Adams, 2007). The GC column oven temperature $\left(70^{\circ} \mathrm{C}\right)$, injecting temperature $\left(250^{\circ} \mathrm{C}\right)$, flow control mode (linear velocity), total flow $(40.8 \mathrm{ml} / \mathrm{min})$ column flow $(1.80 \mathrm{ml} / \mathrm{min})$, pressure $(116.9 \mathrm{kpa})$, linear velocity $(49.2 \mathrm{~cm} / \mathrm{sec})$ and purge flow $(3.0 \mathrm{ml} / \mathrm{min})$ were employed for this analysis. A sample volume of $8.0 \mu \mathrm{L}$ was injected using split mode (split ratio of 20.0). The peak area, that is, the \% amount of every component was calculated by comparing its average peak area to the total areas. Software was used to handle mass spectra and chromatogram. 
Identification of components in the fractions Interpretation of mass spectrum GC-MS was conducted by comparing the database peaks of National Institute Standard and Technology (NIST) library with those reported in literature (Stein et al., 2002). The spectrum of the unknown component was compared with the spectrum of the standards in the NIST library. Component relative percentages were calculated based on GC peak areas without using correction factors. The name, molecular weight and structure of the components were determined.

Evaluation of the Antitrypanasomal Properties of Leptadenia hastate leaf extract

Sixty rats were assigned into five groups (A, B, C, D and $E$ ) of 12 rats per group with each group comprising three replicates of four rats per replicate. Groups A, B and C served as the treatment groups, while groups $D$ and $E$ were the normal control and positive groups respectively. Three different concentrations of the aqueous extract were administered to the different treatment groups according to their body weight. Group A was given $100 \mathrm{mg}$ per kilogram body weight $\left(\mathrm{kg}^{-1} \mathrm{bw}\right)$ of the aqueous preparation of the extract, while groups Band $C$ were administered $300 \mathrm{~kg}^{-1}$ bw and $500 \mathrm{~kg}^{-}$ ${ }^{1}$ bwrespectively. The normal control groups (Group D) were given appropriate volume of distilled water. The positive control groups (group E) were inoculated and treated with a standard drug berenil $\left(3.5 \mathrm{~kg}^{-1} \mathrm{bw}\right)$.All the doses were administered once daily orally for 28 days for all the groups using gastric gavage (Ogbadoyi et al., 2011).

Antitrypanosomal activity of the partitioned fractions

About 20 albino mice with weight $23-30 \mathrm{~kg}$ were used for antitrypanosomal activity of the fractionated extract which were all inoculated with $T . b$. brucei and then grouped into 6 different groups as thus: Groups $A, B, C$ and $D$ in this category served as the treatment groups, while groups $E$ and $F$ were the normal control and positive groups respectively. The experiment was repeated using the most effective dose from above ( $300 \mathrm{~kg}^{-1} \mathrm{bw}$ ).Groups A, B, C and D in this category were treated with $300 \mathrm{~kg}^{-1} \mathrm{bw}$ of $n$-hexane, methanol, dichloromethane, ethyl acetate extracts respectively. The normal control groups (Group E) were given appropriate volume of distilled water. The positive control groups (Group F) were inoculated and treated with a standard, berenil $\left(3.5 \mathrm{~kg}^{-1} \mathrm{bw}\right)$.All the doses were administered once daily orally for 28 days for all the groups using gastric gavage (Ogbadoyi et al., 2011).

\section{Antitrypanosomal Studies}

The antitrypanosomal evaluation was carried out for both the crude extract and the partitioned fractions of the plant sample as described by standard methods (Ogbadoyi et al., 2011)using albino mice.

\section{Packed Cell Volume Measurement}

Heparinized capillary tubes were used for collection of blood from the tail of each mouse. The capillary tubes were filled with blood up to three quarter of their volume and sealed at the dry end with sealing clay. The tubes were then placed in a micro-hematocrit centrifuge (GelmaAwhksley, England) with the sealed end outwards and centrifuged for $5 \mathrm{~min}$ at 11,000 $\mathrm{rpm}$. The tubes were then taken out of the centrifuge and PCV was determined using a standard MicroHematocrit Reader(Ogbadoyi et al., 2011).

\section{Weight of the Animals}

The body weights of animals in each group were monitored before the commencement of the experiment and after the first and second week of treatment to predict the effectiveness of the crude extract and partitioned fractions (Ogbadoyi et al., 2011).

\section{Parasitaemia Measurement}

Thin smears of blood were made from the tail of each mouse on day 4 for Peter's test and on day 3-7 for Rene's test. The smears were applied on microscope slides (76 × $26 \mathrm{~mm}$; Menzel-Glaser Germany), fixed with absolute methanol for $15 \mathrm{~min}$ and stained with $10 \%$ Geimsa stain at pH 7.2 for 15 min. The stained slides were then washed gently using distilled water and air dried at room temperature. Two stained slides for each mouse were examined under Olympus microscope with an oil immersion nosepiece of $100 \times$ magnification. Five different fields on each slide were examined to calculate the average parasitaemia (Ogbadoyi et al., 2011).

\section{Screening of Antitrypanasomal Activity}

The crude plant extracts and partitioned fractions of any active principle of the plant were taken through toxicological evaluations. This was done by using albino mice of similar age and weight (male and female). The plant extract in serial dilution of various concentrations were given to theanimals'intraperitonially(Ogbadoyi et al., 2011).

\section{Acute Toxicity Test}

The acute toxicity of the extract wasdone using Lorke's method (Lorke's, 1983) with modifications by dividing it in to two phases. Phase 1: Nine mice were divided into three equal groups. The three equal groups were administered orally with graded doses $(10,100$ and $1000 \mathrm{mg} / \mathrm{kg}$ respectively) of the extract. Phase 2: Another nine mice were divided into three equal groups, which received graded doses (1600, 2900 and $5000 \mathrm{mg} / \mathrm{kg}$ ) of the extract respectively. The number of deaths in each group within $24 \mathrm{~h}$ was recorded and the final $\mathrm{LD}_{50}$ values were calculated as the geometric mean of the highest non-lethal dose (with no deaths) and the lowest lethal dose (where deaths occurred).

\section{Statistical analysis}

Results were expressed as mean \pm standard error of mean (SEM)of at least four animals in each group. The mean were analyzed using student's test. Differences with values of $p<0.05$ were considered statistically significant.

\section{RESULTS \\ Phytochemical Composition of Crude extract of Leptadenia hastata leaf}

The phytochemical analysis revealed the presence of the following phytoconstituents: alkaloids, tannins, saponins, flavonoids, steroids, terpenoids and phenols as shown in Table 1. 
Bajopas Volume 10 Number 2 December, 2017

Table 1: Preliminary Qualitative Phytochemical Analysis of the Crude Extract of Leptadenia hastata

\begin{tabular}{|c|c|c|}
\hline Chemical Constituent & Chemical Test & Inference \\
\hline Saponins & Frothing test & + \\
\hline \multirow[t]{2}{*}{ Steroids } & $\begin{array}{l}\text { Salkowskii's test } \\
\text { Liebermann }\end{array}$ & + \\
\hline & Burchard's test & + \\
\hline Tannins & $\begin{array}{l}\text { Test with iron salt } \\
\mathrm{K}_{4} \mathrm{Fe}(\mathrm{CN})_{6}\end{array}$ & + \\
\hline \multirow[t]{3}{*}{ Alkaloids } & Hager's reagent & + \\
\hline & Wagner's reagent & + \\
\hline & Marquis' reagent & + \\
\hline Terpenoids & $\begin{array}{l}\text { Liebermann } \\
\text { Burchard's test }\end{array}$ & + \\
\hline Flavonoids & Ammonia test & + \\
\hline Anthraquinone & Borntrager's test & + \\
\hline Resin & & - \\
\hline \multirow[t]{2}{*}{ Solubility test in } & Water & + \\
\hline & Acetone & - \\
\hline
\end{tabular}

Table 2: Quantitative Phytochemical Composition of the Crude leaf extract of Leptadenia 4astate

\begin{tabular}{lc}
\hline Chemical Constituents & Quantity $(\mathrm{mg} / 100 \mathrm{~g})$ \\
\hline Saponins & $52.80 \pm 3.40$ \\
Alkaloids & $96.7 \pm 5.93$ \\
Tannins & $14.20 \pm 0.21$ \\
Phenols & $23.90 \pm 0.13$ \\
Flavonoids & $0.24 \pm 0.01$ \\
\hline
\end{tabular}

Antitrypanosomal activity of the crude extract of Leptadenia hastata

The trypanosomal activity of the crude extract at various doses used is represented in Figure 1. It shows that the group treated with $300 \mathrm{mg} / \mathrm{kg}$ body weight survived for 30 days post treatment with minimum level of parasitaemia.

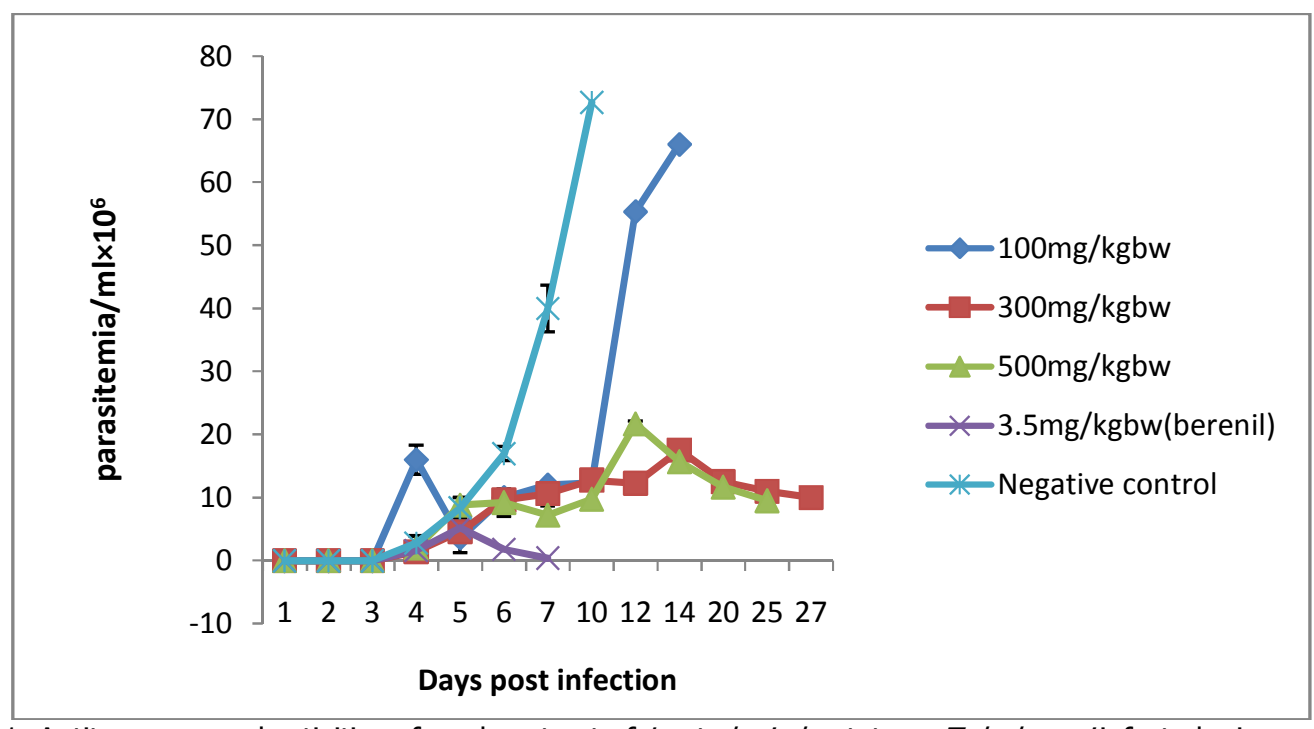

Figure1: Antitrypanosomal activities of crude extract of Leptadenia hastata on T. b. brucei infected mice

Antitrypanosomal activity of the most effective dose $(300 \mathrm{mg} / \mathrm{kg}$ body weight)

The most effective dose (300 mg/kg body weight) of the partitioned fractions is shown in Figure 2. It cleared parasites from circulation with a prolonged survival period of 35 days. 
Bajopas Volume 10 Number 2 December, 2017

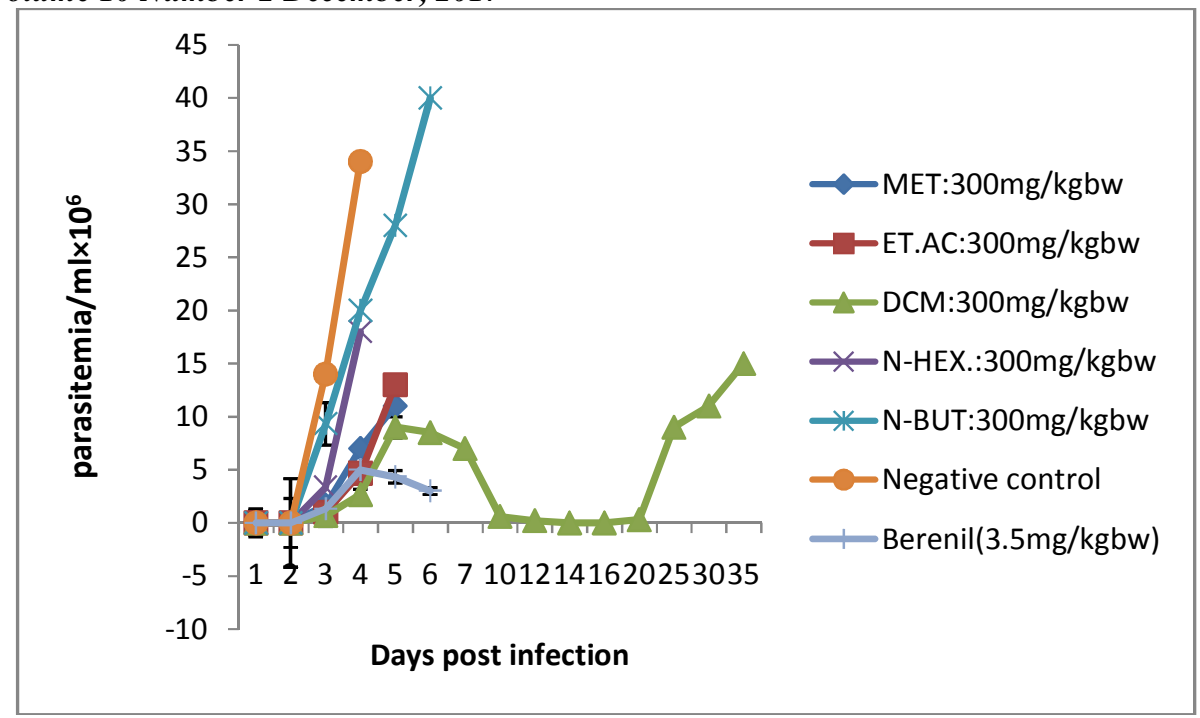

Figure 2: Antitrypanosomal activities of the partitioned fractions on $T . b$. brucei infected mice.

\section{Antitrypanosomal activities of the combined fractions}

The trypanosomal activity of the combined fractions is shown in Figure 3. It cleared the parasites from circulation for 10 days post infection.

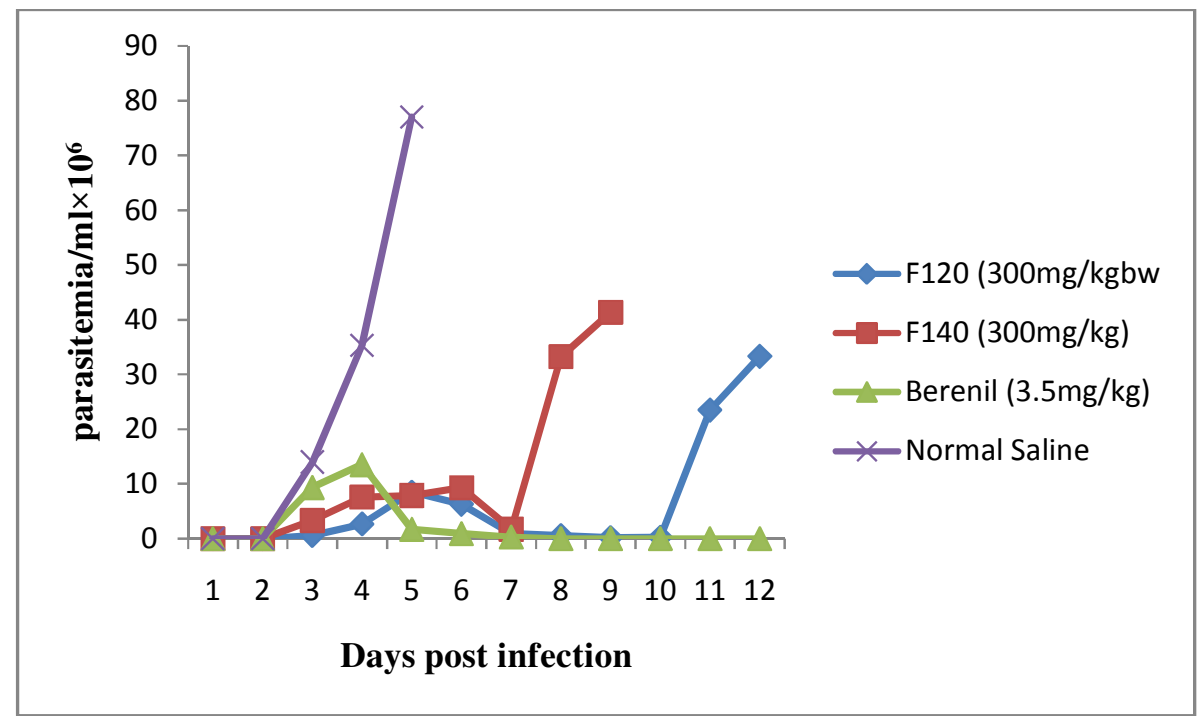

Figure 3: Antitrypanosomal activities of the combined Fractions on T. b. brucei infected mice.

Chemical Compounds Deduced from GC-MS Spectrum of first combined fractions $\left(\mathrm{F}_{20}{ }^{-30}\right)$ The GC-MS spectrum of the first combined fractions of Leptadenia hastata after column chromatography and confirmation using thin layer chromatography (Table 3 ) revealed the presence of sixteen (16) compounds, namely azulene bicyclo (4.4.1) undeca- 1,3,5,7,9 $(0.75 \%)$, pentane $(1.13 \%)$, acetic acid $(0.93 \%)$, 5- tetradecene $(0.45 \%)$, hexadecane $(1.14 \%)$, 7hexadecane $(0.61 \%)$, tridecane $(0.63 \%)$, 9heptadecanone $(0.86 \%)$, pentadecanoic acid $(3.47 \%)$, hexadecanoic acid (5.14\%), 11octadecanoic acid (0.92\%), E-2-tetradecen-1-ol $(10.9 \%)$, tetradecanol $(9.52 \%)$, di- $n$-octyl phthalate (4.54\%), 4,5-2H-oxazole-5-one (12.67\%) and cyclodocosane (46.4\%). 
Bajopas Volume 10 Number 2 December, 2017

Table 3: Chemical Compounds Deduced from GC-MS Spectrum of first combined fractions $\left(\mathrm{F}_{20}{ }^{-30}\right)$

\begin{tabular}{clllc}
\hline $\mathrm{S} / \mathrm{N}$ & Name of Compound & Molecular Formula & $\%$ Area & Flow rate \\
\hline 1 & Azulene & $\mathrm{C}_{10} \mathrm{H}_{8}$ & 0.75 & 10.200 \\
2 & Bicyclo [4.4.1] undeca-1,3,5,7,9 Pentane & $\mathrm{C}_{11} \mathrm{H}_{10}$ & 1.13 & 11.580 \\
3 & Acetic acid & $\mathrm{C}_{10} \mathrm{H}_{11} \mathrm{ClO}_{2}$ & 0.93 & 13.042 \\
4 & 5-Tetradecene & $\mathrm{C}_{14} \mathrm{H}_{28}$ & 0.45 & 15.050 \\
5 & Hexadecane & $\mathrm{C}_{16} \mathrm{H}_{34}$ & 1.14 & 15.150 \\
6 & 7-Hexadecene & $\mathrm{C}_{16} \mathrm{H}_{32}$ & 0.61 & 17.483 \\
7 & Tridecane & $\mathrm{C}_{13} \mathrm{H}_{28}$ & 0.63 & 17.567 \\
8 & 9-Heptedecanone & $\mathrm{C}_{17} \mathrm{H}_{34} \mathrm{O}$ & 0.86 & 19.008 \\
9 & Pentadecanoic acid & $\mathrm{C}_{17} \mathrm{H}_{34} \mathrm{O}_{2}$ & 3.47 & 19.807 \\
10 & Hexadecanoic acid & $\mathrm{C}_{18} \mathrm{H}_{36} \mathrm{O}_{2}$ & 5.14 & 20.883 \\
11 & 11-Octadecanoic acid & $\mathrm{C}_{19} \mathrm{H}_{36} \mathrm{O}_{2}$ & 0.92 & 22.442 \\
12 & E-2-Tetradecen-1-ol & $\mathrm{C}_{14} \mathrm{H}_{28} \mathrm{O}$ & 10.9 & 24.208 \\
13 & Tetradecanol & $\mathrm{C}_{4} \mathrm{H}_{28} \mathrm{O}$ & 9.52 & 27.208 \\
14 & Di-n-octyl phthalate & $\mathrm{C}_{24} \mathrm{H}_{38} \mathrm{O}_{4}$ & 4.54 & 27.00 \\
15 & $4,5-2 \mathrm{H}-$ oxazole-5-one & $\mathrm{C}_{25} \mathrm{H}_{29} \mathrm{NO}_{3}$ & 12.7 & 29.905 \\
16 & Cyclodocosane & $\mathrm{C}_{24} \mathrm{H}_{48}$ & 46.4 & \\
\hline
\end{tabular}

\section{DISCUSSION}

The result of the phytochemical screening of Leptadenia hastataleaf extract revealed the presence of alkaloids, steroids, flavonoids, tannins, saponins, terpenoids and anthraquinone which is in line with earlier report ofBello et al. (2011)on Leptadenia hastata leaves. Moreover, the phytochemical analysis of the dichloromethane and ethylacetate fractions of Leptadenia hastata suggested that they are highly concentrated with saponins. However, saponins bind cholesterol; block its uptake by the intestines thus facilitating its excretion as well as the coagulation of the red blood cells (Okwu and Josiah, 2006). Saponins also have the ability to kill or inhibit cancer cells (Okwu, 2005; Okwu and Emenike, 2006). These phytochemicals were found in the extracts of Leptadenia hastata in a high concentration of $(52.80 \mathrm{mg} / 100 \mathrm{~g})$.

Plants of different families could possess different trypanocidal activity (Freiburghaus et al.,1996).Thus, the presence of saponins in this plant could be explored for the possible application in medicine.The alkaloid value of sample $96.7 \pm 5.93 \mathrm{mg} / 100 \mathrm{~g}$ was higher than the $1.46 \pm 0.01 \mathrm{mg} / 100 \mathrm{~g}$ reported by Oyetayo et al.(2012) for Luffa cylindrica seed, but still within the permissible limit. These phytochemical components present could be responsible for suppressing parasite proliferation in treated animals. The other fractions containing tannins, flavonoids, alkaloids and anthraquinones, were weakly active against parasite proliferation. This suggested that the variation in the anti-trypanosomal efficacy of the different fractions can be attributed to the type and concentration of the metabolites present. Therefore, the trypanocidal potential of the methanol extract of $L$. hastata may be due to its high content of saponins and alkaloids or the interaction of these major components with other minor phytochemical constituents. However, further work is required to confirm this assertion.

A lot of antitrypanosomal medicinal plants from the Nigerian flora have been shown to possess potentials to combat trypanosomiasis (Nwodo et al., 2015). It is therefore not surprising that the plant tested (Leptadenia hastata) showed promising trypanocidal effect. For animals treated with the crude extract at different dose levels, only the animals that received $300 \mathrm{mg} / \mathrm{kg}$ and $500 \mathrm{mg} / \mathrm{kg}$ body weight survived beyond 20 days post treatment. The most effective dose (300 mg/kg body weight) however survived for 25 days post treatment. From the phytochemical studies, the type of compounds which could be responsible for the antitrypanosomal activities are associated with the metabolites and the results obtained showed that both the crude and partitioned extract of $L$. hastata contained some metabolites that suppressed the activity of the trypanosomes rather than killing the parasites completely. The animals treated with the partitioned fractions were treated with the same dose levels of $(300 \mathrm{mg} / \mathrm{kg}$ ) body weight. The animals treated with the dichloromethane fraction survived for 40 days post infection with minimum level of parasitaemia. The present study has provided evidence that bothextracts exhibit trypanostatic effect which is often associated with reduction in anemia and promotes weight gain in experimental African trypanosomiasis (Mulumba, 2003). Anaemia is the most outstanding clinical and laboratory feature of African trypanosomiasis(Bizimana et al., 2006) and also the primary cause of death. The leaves of $L$. hastata are used in treating hypertension and diarrhea. Trypanostatic effect of the plant extracts were explained with corresponding increase in PCV which prolong the lifespan of treated animals by reducing the parasite load or neutralizing the toxic metabolites produced by trypanosomes (Abubakar et al., 2005). Based on these results and the fact that plant part extracts are traditionally used in the treatment of African Trypanosomiasis. Although the parasitaemia level totally disappeared before the end of treatment but reappeared before their death period. The results of the present study confirmed that the use of medicinal plants in folk medicine contributes significantly to primary health care, and that natural products are potential sources of new drugs for the treatment of important tropical diseases caused by trypanosomes. The components shown by GC-MS may be the active principles that were present in a low proportion in the extract were responsible for the activity for 10 days or it could be that synergistic effects is exhibited by the extract. 
The active principles with their retention time (RT), molecular formula, molecular weight, and concentration (\%) are presented in (Tables 1, 2, 3 and 4). The chemical constituents observed in the extracts include phthalic; 1, 2-benzenedicarboxylic, hexadecanoic and octadecanoic acids which may be involved in antagonism against bacteria (Al-Saif et al., 2013). These observed compounds have also been reported to have antioxidant, hypocholesterolemic, hemolytic, antiinflammatory, anticancer, antibacterial, nematicide and antihypertensive activities (Nwodo et al., 2015). These bioactive compounds mainly comprised of carboxylic derivatives may be involved in the observed pharmacological activity. This is in line with the findings of Mann and Ogbadoyi (2012) using different plant extracts which showed both trypanocidal and trypanostatic effects. It seems plausible to infer that the active ingredient acts as intact glycosides and not as free saponins since preliminary treatment using the oral route did suppress parasitaemia. Saponins are not known to be toxic when given orally as they are easily hydrolyzed by biotransformation to non-toxic (non-hemolytic) compounds (Sofowora, 1993).

After Column Chromatography of the most active fraction were obtained, the purity of the fraction is improved upon, thereby ending with fewer components as shown in the chromatograms (Figure 4). The chemical constituents observed from the GCMS analysis in the extracts include phthalic acid, 1, 2benzenedicarboxylic acid, hexadecanoic and octadecanoic acid which may be involved in antagonism against bacteria (Al-Saif et al., 2013). Similarly, these observed compoundsmay be antagonistic against trypanosomes, since have also been reported to have antioxidant, hypocholesterolemic, anti-inflammatory, anticancer, antibacterial, and antihypertensive activities (Anushaet al., 2012). However, most of these

\section{REFERENCES}

Abiodun, O.O.,Gbotosho, G.O., Ajaiyeoba, E.O.,Brun, R. and Oduola, A.M. (2012). Antitrypanosomal activity of some medicinal plants from Nigerian ethnomedicine.Parasitology Research, 110, 521-526.

Abubakar, A., Iliyasu, B., Yusuf, A.B., Onyekwelu, N.A., Igweh, A.C., Afolayan,D.O. and Ogbadoyi, E.O (2005).Antitrypanosomal and hematological effects of selected Nigerian medicinal plants in Wistar rats.Biokemi-stri, 17, 95-99.

Adams, R.P. (2007). Identification of Essential Oil Components by Gas chromatography/Quadrupole Mass spectroscopy. Allured Publishing Corporation, Carol Stream, Illinois, USA.

Aliero, A.A. and Wara, S.H. (2009).Validating the medicinal potential of Leptadenia hastata. African Journal of Pharmacology, 3, 335-338.

Al-saif, U. and Birnin-Yauri, U. A. (2013).Partial Purification and Characterization of Extracellular Protease from Peddicoccus traditional practices consist of different herbal concoctions from different plants (Atawodiet al.,2002), therefore it is possible that in those combined herbal therapy involving $L$. hastata contributes to the suppression of the parasitaemia and allow active principle for other component of the mixture to easily wipe out the remaining parasites. This kind of studies will serve as a starting point for future studies for the discovery of better trypanocidal molecule(s); some of the compounds isolated have been tested for antitrypanosomal properties.

\section{CONCLUSION}

Most of the medicinal plant species used in Nigeria as traditional medicine to eliminate symptoms of trypanosomiasis have so far been successful and many interesting extracts and chemical constituents have been earmarked for further investigation following in vivo anti-trypanosomal activity evaluation as discovered by this research.

\section{CONTRIBUTIONS OF THE AUTHORS}

Dr. Mann is involved in the conception anddrafting of the study, literature search, acquisition of data, analysis and interpretation of data and general supervision of the study. Prof. Ogbadoyitakes the responsibility of design, definition of intellectual content, and revising it critically for important intellectual content, experimental studiesand manuscript editing. Mrs. Haruna carry out data acquisition,literature search, analysis and experimental studies, and statistical analysis.

\section{ACKNOWLEDGEMENTS}

The Authors are thankful to the authority of Federal University of Technology, Minna, NigerState, Nigeria for providing laboratory facilities in conducting thisresearch work.

\section{COMPETING INTERESTS}

Authors have declared that no competing interest exists.

acidilacti. Nigerian Journal of Basic and Applied Sciences, 16 (1), 87-89.

Anusha, O.B. (2012). Potentials of Kerstingiellageocarpa as a health food. Journal of Medicinal Food, 12(1), $184-187$.

Atawodi, S.E., Ameh, D.A., Ibrahim, S., Andrew, J.N., Nzelibe, H.C., Onyike, E, Anigo, K.M., Abu, E., James, D.B., Njoku, G.C. and Sallau, A.B. (2002). Indigenous knowledge system for treatment of trypanosomiasis in Kaduna State of Nigeria. Journal of Ethnopharmacology, 79, 279-282.

Bello, A., Aliero, A.A., Saidu, Y. and Muhammad, S (2011).Phytochemical Screening,Polyphenolic Content and Alpha-Glucosidase Inhibitory Potential of Leptadenia hastata (Pers.) Decne.Nigerian Journal of Basic and Applied Science, 19, 181-186.

Betti, J.L., Yemefa'a, S.R., Nchembi, M.andTarla, F. (2011). Contribution to the knowledge of non-wood forest products of the far north region of Cameroon: Medicinal plants sold in the Kousséri market. Journal of Ecology and Natural Environment, 3, 241-254. 
Bizimana, N., Tietjen, U., Zessin, K.-H., Diallo, D., Djibril, C., Melzig, M.F.and Clausen, P.-H., (2006). Evaluation of medicinal plants from Mali for their in vitro and in vivo trypanocidal activity. Journal of Ethnopharmacology, 103(3), 350-356.

Burkill, H.M. (1997). Useful Plants of Western tropical African. Royal Botanic Garden, Kew, 4,969.

Dambatta, S.H. and Aliyu, B.S. (2011). A survey of major ethnomedicinal plants of Kano North Nigeria, their knowledge and uses by traditional healers. Bayero Journal of Pure and Applied Sciences, 4, 28-34.

Freiburghaus, F., Kaminsky, R., Nkunya, M.H. and Brun, R. (1996). Evaluation of African medicinal plants for their in vitro trypanocidal activity. Journal of Ethnopharmacology, 55(1), 1-11.

Harborne, J. B. (1998). Phytochemical method: A guide to modern technique of plant analysis. $3^{\text {rd }}$ Ed. Chapman and Hall, New York, 1 $198 \mathrm{pp}$.

Hotez, P.J. andKamath, A. (2009). Neglected tropical diseases in sub-saharan Africa: review of their prevalence, distribution, and disease burden. Problems of Neglecting Tropical Diseases, 3(8), 412.

Ibrahim, M.A., Mohammed, A., Isah, M.B. and Aliyu, A.B. (2014). Anti-trypanosomal activity of African medicinal plants: A review update. Journal of Ethnopharmacology, 154: 26-54

Lorke, D.A. (1983). A new approach to practical acute toxicity testing. Achieves of Toxicology, 53: 275-289.

Mann, A. (2007). Survey of Ethnomedicine for the treatment of Tuberculosis: Chemistry Perspective. Ayanwola Printing Works, ISBN 978-978-085-536-9, Minna Niger State, Nigeria, pp. 117.

Mann, A. and Ogbadoyi, E.O. (2012). Evaluation of Medicinal Plants from Nupeland for Their in vivo Antitrypanosomal Activity. American Journal of Biochemistry, 2(1), 1-6.

Mann, A., Ibrahim, K., Oyewale, A.O., Amupitan, J.O., Fatope, M.O. and Okogun, J.I. (2011).Brine Shrimp Toxicity Evaluation of the Root Bark Extract of Terminalia avicennioides. African Journal of Scientific Research, 4(1), 221-228.

Mulumba, K. (2003). Socio-economic and cultural factors in the research and control of trypanosomiasis: paat technical and scientific series 4. Italy: Food and Agriculture Organization of the United Nations (FAO).

Nwodo, N.J., Ibezim, A., Ntie-Kang, F., Adikwu , M.U. and Mbah,C.J. (2015). Anti-Trypanosomal Activity of Nigerian Plants and Their Constituents. Molecules, 20: 7750-7771.

Ogbadoyi, E.O., Garba, M.H., Kabiru, A.Y., Mann, A. and Okogun, J. (2011). Therapeutic evaluation of Acacia nilotica (Linn) stem bark extract in experimental African trypanosomiasis. International Journal of Applied Research in Natural Products,4, 1118.
Okwu, D. E. (2005).Phytochemicals.Vitamins and Mineral contents of two Nigeria Medicinal Plants.International. Journal of Molecular Medicine and Advance Sciences, 1:375-381.

Okwu, D. E. and Emenike, I.N. (2006). Evaluation of the phytonutrients and vitamins contents of citrus fruits. International Journal of Molecular Medicine and Advance Science, 2(1), 1- 6.

Okwu, D.E. and Josiah, C. (2006).Evaluation of the chemical composition of two Nigerian medicinal plants. African Journal of Biotechnology, 5, 357-361.

Orishadipe, A.T., Okogun, J.I.andMishelia, E. (2010). Gas chromatography - mass spectrometry analysis of the hexane extract of Callindra portoricensis and its antimicrobial activity. African Journal of Pure and Applied Chemistry, 4(7), 131-134.

Oyetayo, O., Adeyemi, F.O. andAdeniran, G.O. (2012).Amino acid, mineral composition and functional properties of some oil seeds. Journal of Agricultural and Food Chemistry, 42(4), $879-881$.

Sofowora, A.E.(1993). Medicinal plants and traditional medicine in Africa, Volume $2.2^{\text {nd } E d n . ~ S p e c t r u m ~ B o o k s ~ L t d, ~ I b a d a n, ~}$ Nigeria; pp. 1-289.

Stein, S., Mirokhin, D., Tchekhovskoi, D. and Mallard, G. (2002). The NIST Mass Spectral Search Program for the NIST/EPA/NIH Mass Spectra Library. Standard Reference Data Program of the National Institute of Standards and Technology. Gaithersburg, MD, US.

Tamboura, H.H., Bayala, B., Lompo, M., Guissou, I.P. andSawadogo, L. (2005). Ecological distribution, morphological characteristics and acute toxicity of aqueous extracts of Holarrhena floribunda(G. Don) Durand \&Schinz, Leptadenia hastata(Pers.) Decne and Cassia sieberiana (dc) used by veterinary healers in Burkina Faso. African Journal of Traditional Complementary and Alternative Medicine, 2, $13-24$.

Togola, A., Austarheim, I., Theïs, A., Diallo, D. and Paulsen,

B.S. (2008).Ethnopharmacologicaluses of Erythrina senegalensis. a comparison of three areas in Mali, and a link between traditional knowledge and modern biological science. Journal of Ethnobiology and Ethnomedicine, 4, 6.

Trease G.E. and Evans W.C.(1989).A Textbook of Pharmacognosy, $13^{\text {th }}$ Edition, BailliereTindall Ltd., London. Pp. 19-21. 